\title{
Investing for long-term value creation
}

\section{Dirk Schoenmaker \& Willem Schramade}

To cite this article: Dirk Schoenmaker \& Willem Schramade (2019) Investing for longterm value creation, Journal of Sustainable Finance \& Investment, 9:4, 356-377, DOI: 10.1080/20430795.2019.1625012

To link to this article: https://doi.org/10.1080/20430795.2019.1625012

$$
\begin{aligned}
& \text { (c) } 2019 \text { The Author(s). Published by Informa } \\
& \text { UK Limited, trading as Taylor \& Francis } \\
& \text { Group }
\end{aligned}
$$

Submit your article to this journal 2

\section{Џll Article views: 901}

\section{Q View related articles $₫$}

View Crossmark data $\asymp$

Citing articles: 2 View citing articles $₫$ 


\title{
Investing for long-term value creation
}

\author{
Dirk Schoenmaker ${ }^{\mathrm{a}, \mathrm{b}}$ and Willem Schramade (D) ${ }^{\mathrm{a}, \mathrm{c}}$ \\ ${ }^{a}$ Rotterdam School of Management, Erasmus University, Rotterdam, The Netherlands; ${ }^{b}$ Equity Department, \\ CEPR, The Hague, The Netherlands; ' Equity Department, NN Investment Partners, The Hague, The Netherlands
}

\begin{abstract}
In the transition to a sustainable economy, companies are increasingly adopting the goal of long-term value creation, which integrates financial, social and environmental value. However, institutional investors struggle to invest for long-term value creation and perform the social function of finance. Traditional investment approaches, based on the neo-classical paradigm of efficient markets and portfolio theory, only capture financial value in their financial risk and return space. Attempts at ESG integration are typically too shallow to overcome this problem. In this paper, we examine the set of issues that make this problem so stubborn and we outline the contours of an alternative paradigm, based on adaptive markets, that is better able to pursue long-term value creation. This long-term investment approach includes short investment chains, active management that assesses companies' transition preparedness, concentrated portfolios, and deep engagement.
\end{abstract}

\section{ARTICLE HISTORY}

Received 21 March 2019

Accepted 26 May 2019

\section{KEYWORDS}

Capital markets; ESG;

financial system; fund management; institutional investors

\section{Introduction}

The erosion of natural capital poses existential threats to national and global prosperity, but political and economic systems are unprepared for responding to that risk (Cohen et al. 2017). The sense of urgency is rising from a low base. The first climate bankruptcy has already happened ${ }^{1}$ but governance, incentives and thinking are still misaligned. The financial and corporate sectors could play an important role in turning the tide by truly managing for long-term value creation. The concept of long-term value creation means that a company aims to optimise its financial, social and environmental value in the long term, making it prepared for the transition to a more sustainable economic model (Dyllick and Muff 2016; Tirole 2017; Schoenmaker 2018). Unfortunately, current business practices are still too narrowly focused on short-term financial returns, meaning that we fail to achieve inclusive capitalism (e.g. Cort 2018). For decades, maximising profits has been the leading objective in corporate finance. However, recent papers (Hart and Zingales 2017) argue for a broader corporate objective than shareholder value in a narrow sense.

CONTACT Willem Schramade schramade@rsm.nl E Rotterdam School of Management, Erasmus University, Postbus 1738, 3000 DR Rotterdam, The Netherlands

This article has been republished with minor changes. These changes do not impact the academic content of the article. 
Hart and Zingales (2017) challenge the prevailing idea that externalities, like charity, can be outsourced to the shareholders. They make a distinction between shareholder value, which aims for maximisation of financial value only, and shareholder welfare, which incorporates social and environmental externalities. An important assumption in their model is that these externalities are linked to a company's operations. So, companies face a choice in the degree of sustainability in their business model. The mechanism in Hart and Zingales (2017) to guide that choice is voting by prosocial shareholders on corporate policy.

The internalisation of externalities is a dynamic process. That means that what is financially viable now can be loss making in the future (and vice versa). Some externalities are already internalised through best business practices at companies, for example, energy and material savings in the production process and cultivating an inspired work force. Further externalities may be internalised in the future under pressure from government interaction, such as regulation and tax, societal pressure, and technological developments, such as low cost solar and wind energy. Companies can anticipate and incorporate externalities by connecting the relevant social and environmental dimensions to their business model (Schramade 2016), making their business model transition prepared. That is in line with the Hart-Zingales model, which assumes that the externalities are connected to a company's production process.

The materiality (or lack thereof) of the social and environmental dimensions is highly context specific. It varies per industry, and also within industries, depending on the nature of the industry, the specific company's business model and local conditions. New evidence indicates that there is a business case for full environmental, social and governance (ESG) integration into investment. Companies that perform well on material ESG issues, also show a superior financial performance (e.g. Clark, Feiner, and Viehs 2015; Khan, Serafeim, and Yoon 2016). This is consistent with the idea that strong management of material ESG issues brings a real competitive advantage.

Institutional investors are increasingly using ESG ratings to incorporate the social and environmental dimensions in the investment process. But these external ratings rely on scanty and sometimes conflicting data (Tirole 2017) and provide only limited information on material ESG factors. Schramade (2016) argues that investing in sustainable companies (defined as companies that optimise financial, social and environmental value in the long term) requires doing fundamental analysis of the business model and the underlying value drivers of investee companies. In that way, fundamental analysts can assess companies' social and environmental value, next to their financial value. Unfortunately, very few investors actually do this.

In this paper, we sketch the set of issues that make this problem so stubborn: the fact that pricing, allocation and performance measurement are all versed in the language of efficient markets; and that the other components of the current paradigm are skewed towards optimisation within that same narrow financial risk-return framework. Long and complicated investment chains -from the ultimate provider of capital to the ultimate user of capital- mean that incentives are distorted, the horizon gets shorter with each extra party in the chain and meaningful information is lost along the chain (Neal and Warren 2015).

We outline the contours of an alternative paradigm that is better able to pursue long term value creation (summarised in Figure 1). It breaks away from efficient market thinking and assumes adaptive markets where the incorporation of sustainability information into stock prices is an adaptive process, of which the success is dependent on the 


\begin{tabular}{|l|l|l|}
\hline Dimension & Old paradigm & New paradigm \\
\hline Pricing & EMH & AMH \\
\hline Allocation & Factors, indices and ratings & $\begin{array}{l}\text { Long-term value creation po- } \\
\text { tential }\end{array}$ \\
\hline Performance measurement & Financial & Financial \& extra-financial \\
\hline ESG considerations & $\begin{array}{l}\text { Shallow: ESG as an overlay } \\
\text { Max F }\end{array}$ & $\begin{array}{l}\text { Deep: assessing transition } \\
\text { preparedness } \\
\text { Max F+S+E }\end{array}$ \\
\hline Favoured approach & Passive, limited engagement & Active, deep engagement \\
\hline Investment chain & Long \& complex & Short \\
\hline Role for asset management & Efficiency / aggregation & $\begin{array}{l}\text { Financial performance \& so- } \\
\text { cial function of finance }\end{array}$ \\
\hline
\end{tabular}

Figure 1. Contours of an alternative paradigm. Note: $\mathrm{EMH}=$ Efficient Markets Hypothesis; $\mathrm{AMH}=$ Adaptive Markets Hypothesis; $F=$ Financial; $S=$ Social; $E=$ Environmental.

number of fundamental analysts engage in transition preparedness analysis - and the speed and quality of their learning; where investment chains are short, engagement is deep. In such a setting, the financial system can fulfil its main task of allocating funding to its most productive use, and achieving long term value creation.

Getting there requires a change of mindsets, which can be achieved by integrated sustainable finance education and incentives from governance and regulation. This will take time, but the first steps are being taken by advanced asset managers, asset owners, and regulators.

This paper is organised as follows. Section 2 discusses how the current paradigm suffers from an overreliance on market metrics and complicated investment chains. Section 3 then outlines what an alternative paradigm could look like and how it could be achieved. Finally, Section 4 concludes.

\section{The current investment paradigm and its (over) reliance on market metrics}

The efficient markets hypothesis and portfolio theory have been so influential over the past five decades that they pervade the language and thinking of asset management. These theories also established the separation of finance and ethics. Traditional finance is consistent with the argument of Friedman (1970) that 'the business of business is business'. In this view, it is the task of the government to take care of social and environmental concerns. This separation between finance and societal concerns seems especially true in the US (Simon 2017) but it applies to the entire global financial system, which is dominated by US asset managers and US investment banks. It is second nature for investors to think and communicate in market benchmarks and market risks. This naturally affects the functions of pricing, allocation and performance measurement in the investment process. It also affects how sustainability is integrated; what investment approaches are favoured; the complexity of investment chains; and the role of asset managers.

\section{1. 'Efficient' pricing makes blind}

The efficient markets hypothesis assumes that all relevant information of a company is incorporated in that company's stock or market price (Fama 1970). So, investors 
cannot systematically beat the market. The market is supposed to be so efficient that it immediately incorporates all relevant new information, making it impossible for investors to benefit from superior insights or information. While there are differences in risk-return profiles across assets, these assets are assumed to be priced accordingly. Arbitrage makes sure that prices stay correct: abnormally high return assets immediately attract more fund flows, which drive up prices and reset expected returns back to the market rate. As a result, in the world of efficient markets, all information is incorporated in stock prices.

However, there is plenty of evidence that markets are not always efficient. Whereas the efficient markets hypothesis assumes perfectly rational investors, a vast body of behavioural finance literature has shown since the 1970s that people (including investors) are far from rational (e.g. the early work by Tversky and Kahneman (1973), the review article by Barberis and Thaler (2003)). The efficiency of markets has also been questioned by strong evidence on the momentum factor, which shows that stocks that have done well over the past few months tend to continue to do well over the next several months (Jegadeesh and Titman 1993). Behavioural finance indicates that such lack of rationality has important implications for financial markets, which can be seriously overvalued or undervalued for extended periods of time. More recently, these behavioural anomalies have been supplemented by sustainability anomalies (e.g. Khan, Serafeim, and Yoon 2016). This indicates that pricing is a far from perfect signal, which should not be followed blindly.

\subsection{Allocation close to the market}

The capital asset pricing model built on modern portfolio theory (Markowitz 1952) stresses that risk is an inherent part of higher reward. Importantly, risk and return characteristics should not be considered in isolation per security, but by how much the investment affects the overall portfolio's risk and return. One can construct an efficient frontier of optimal portfolios that maximise expected return for a given level of risk, leading to an efficient economic allocation (e.g. Elton et al. 2014). In the capital asset pricing model, the only relevant variable to determine a stock's return is its sensitivity to the market, which is called systematic risk. The non-systematic or idiosyncratic risk is not priced. In equilibrium, all investors hold the market portfolio, which is replicated in the market index. It suffices to adopt a passive investment approach by investing in the market index. That is a very strong idea indeed. And in practice most investors indeed seem to be positioned close to the market. But the problem is the narrow view on financial risk and return, ignoring the social and environmental dimensions. Even the measure of financial risk is rather narrow, as it is based solely on the volatility of past stock returns, which not necessarily captures future financial risk, let alone the fundamental risks of the companies in the portfolio.

\subsection{Narrow performance measurement}

Performance measurement is also versed in the language of portfolio theory. The narrow financial risk-return thinking has led to a strong focus on the stock price as central performance measure for executive and investor performance. The traditional way of performance measurement is the benchmarking of an investor's returns to those of the relevant market index, which is confined to the financial risk and return dimension. 
Market benchmarks are indices, such as the MSCI World Index or the MSCI All Country World Index, that consist of a basket of the largest companies by market capitalisation in a certain market (i.e. the global stock market, a regional market like Developed Asia or a sector like Real Estate). The underlying idea is that the index represents 'the market'. When assessing a fund manager's performance, his or her performance will be measured against such a benchmark (was it higher or lower over the past 5 years, 3 years, 1 year, 6 months, 1 month, and 1 day?), correcting for the amount of risk the fund manager took in achieving that result.

Measures for such market risk-taking include beta, tracking error, information ratio and Sharpe ratio (e.g. Elton et al. 2014). These performance measures relate a portfolio's return to the market return (or the risk free rate return), which is calculated in a financial risk-return space. In this view, there is no need to analyse the companies in the portfolio themselves; only the sensitivity of the portfolio's return to the market. The social and environmental dimensions are not included in these performance measures. And how can markets maximise long term value if its major components are not measured?

\subsection{ESG considerations as an overlay; and the limitations of ESG ratings}

Several efforts have been made to supplement the market metrics with ESG ratings and ESG indices. But they only help to some extent. Like Corporate Social Responsibility (CSR) on the corporate side, they do not address the core of the issue. Rather, they consider ESG as an add-on to financials and business models, instead of as a driver of business models and financials. That is also how most investment professionals have been using ESG ratings and ESG indices: as yet another indicator that may look good or bad, but which hardly affects their investment decisions.

The advantage of these ESG ratings is that they provide investors with a quick approximation of a firm's ESG quality, just like a price-earnings ratio provides investors with a quick view on a firm's valuation. However, just like valuation multiples, ESG ratings are merely imprecise shortcuts and one should be vigilant of errors.

In fact, ESG ratings have a number of limitations by design. First, ratings want to be too many things to too many people. They have little focus on material issues (i.e. issues that are relevant to the investee companies), while it is crucial for investment purposes to focus on material issues (Khan, Serafeim, and Yoon 2016). This means that a materially negative (and potentially fatal) issue is easily cancelled out by high scores on immaterial items, resulting in serious mistakes, which would have been spotted in a diagnosis by a seasoned analyst. For example, the software fraud at Volkswagen was not very surprising given the major governance issues at the firm, with fighting shareholders and the local government pushing to maximise financial returns and employment at the expense of environmental standards. Although these issues were well flagged, Volkswagen nevertheless got very high ratings with most of the ESG rating agencies as it ticked many positive boxes on other issues.

Second, the ratings are based on reported data and policies, which is only a fraction of what is needed for a good assessment and sometimes even conflicting (Tirole 2017). Moreover, it creates biases in scores, for example, on size (as they favour large companies with big sustainability staff departments) and region (higher scores for European companies). Yet other firms, especially small ones, get low ratings since they do not put enough 
information on their policies in the public domain; or they get misclassified and compared with the wrong kind of firms.

Third, scores are 'industry neutral' and based mainly on operations, while hardly taking into account the products of the companies in question. This can result in ratings that are intuitively wrong, as the least bad companies in very unsustainable industries (say coal or tobacco) still get very high scores and can be named sustainability leaders.

Finally, there are too many stocks (as many as 70) covered per analyst, which also makes an in-depth assessment unlikely. While the ESG ratings agencies do aim to address these design limitations, they seem trapped in their own frameworks, which they are reluctant to change because they want to maintain consistency in their data.

Hence, it is not surprising to see a lack of correlation in scores between ratings agencies. Across 1600 stocks in the MSCI World benchmark, Howard (2016) finds a correlation of $26 \%$ between the scores assigned by the two largest rating agencies. Based on survey data, Mooij (2017a) concludes that 'reporting fatigue, a lack of convergence and the (sometimes) poor quality and transparency have made the ESG rating industry more vice than virtue in the adoption of responsible investment'.

In sum, ESG ratings need to get better. Investors should not accept them as the conclusion on a company's sustainability quality, but rather as a starting point for analysis. What is more, they should reconsider some of their core assumptions to really embed ESG in their investment process.

\subsection{Passive as the favoured investment approach}

The pervasiveness of efficient markets thinking also affects the choice of investment approaches. Since all information is supposedly incorporated in stock prices, one could argue that everyone should do passive investing, as there are no benefits from active investing. The industry has increasingly been buying this argument, also since passive investing minimises visible costs (i.e. fees) as well as career risks for investors and consultants. And indeed, why would one buy the more expensive active approach if it fails to deliver what it should, namely better long-term value creation and returns?

Some even argue that passive is inherently more sustainable as holding periods are much longer. That argument is flawed though, as long-termism is not about long holding periods but about long-term views on the economic viability of your investments. This should drive decisions - which can imply that you sell a stock now as you do not believe in its long-term survival.

The real strength of passive investing is that it involves huge amounts of capital that can be moved across types of passive investing, i.e. across asset classes, and potentially also from unsustainable to sustainable companies. However, its allocational role is ultimately limited as it cannot really distinguish between sustainable and unsustainable business models. Indices based on ratings (and their abovementioned problems) cannot do that. Sustainable indices with exclusions of say tobacco have been an important step forward, as they at least allow investors to avoid allocating capital to the worst models. But they still do not select for opportunities, let alone long term value creation. Over time this should get better, especially if voting and engagement on passive holdings becomes linked to fundamental analysis of the underlying holdings. Active and passive investments can then reinforce each other. 


\subsection{Long and complex investment chains}

Long investment chains exacerbate the reliance on market metrics, as each party wants to monitor the investment performance of the next party in the chain. Along the chain, a lot of valuable information is lost. In institutional investment, there is a long and complicated chain of parties that sit between the ultimate provider of capital (typically someone investing for his or her retirement) and the ultimate user of capital (typically a company or project). In their simplest form, such investment chains look like Figure 2. But in practice, such chains are much more complicated than suggested by Figure 2, because beneficiaries have investments with multiple asset owners (pension funds of current and past employment; several insurance products) and multiple asset managers. In an investment chain, there is a principal-agent relationship between the parties at each link, with implications for allocation and performance. The investment performance of the asset manager is, for example, measured against a clearly articulated market benchmark.

Investment decisions are often made across multi-layered asset owner organisations supported by multiple consultants and ratings agencies. A pension fund, for example, typically has a long internal chain:

- Beneficiaries (pensioners and future pensioners);

- Governing board;

- $\mathrm{CEO}$ and/or CIO;

- Asset class heads;

- Supporting functions like finance, accounting, legal, and compliance;

- External and internal asset managers.

Delegated investment management - with multiple parties in the investment chain causes agency problems between the asset owner or principal on the one hand and the delegated asset manager or agent responsible for making investment decisions on the other hand. Investment objectives, risk appetite, incentives, horizons and knowledge are

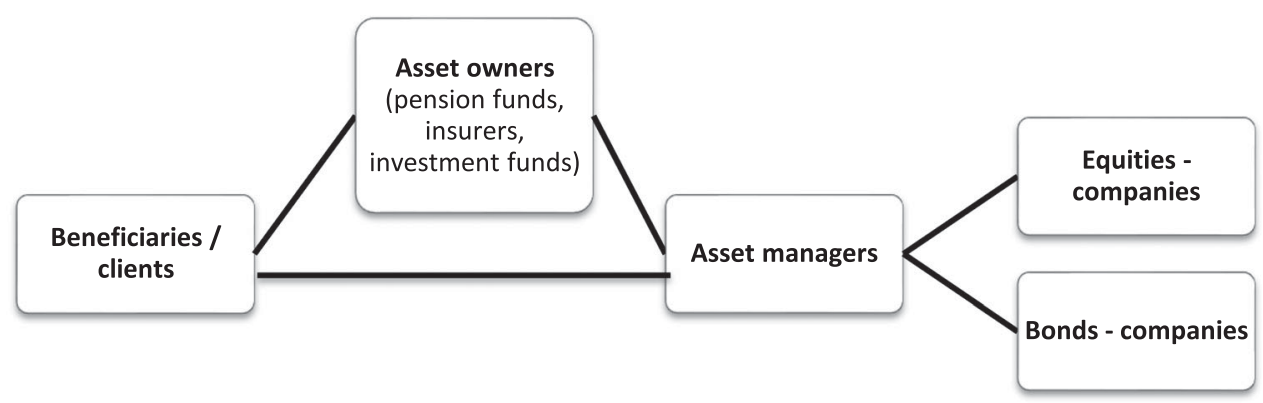

Investment

Returns

Figure 2. A stylised investment chain. 
typically not fully aligned, neither across nor within organisations. These problems are exacerbated when investing for the long term, where the payoff is distant and often highly uncertain (Neal and Warren 2015). The human reflex is to battle such uncertainty by focusing on short-term metrics that can be measured.

Problems arise from differences in investment horizons, a tendency to evaluate and reward based on short-term results and a failure to commit. While an institutional investor might wish to pursue a long-term investment strategy for its beneficiaries, it might also use a quarterly benchmark to evaluate its asset managers internally. Next, an institutional investor might appoint internal and external gatekeepers to benchmark them against each other. In such a setting, it is very difficult to avoid tactical investment decisions aimed at short-term investment gains.

\subsection{A limited role for asset management}

In the current setting, the role of asset management firms seems limited to providing efficiency and aggregation, especially as the belief in their alpha generating capabilities has faded. With efficient market thinking, people seem to have forgotten about their social function. However, a much bigger role for asset management looms in a paradigm aimed at long-term value creation, as its success depends on services that need to be provided by asset managers, most notably analysing companies' transition preparedness (see section 3.4).

\section{Contours of a new paradigm}

This section proposes the elements of a new paradigm that is geared towards long term value creation. The backbone of such a paradigm is an active investment approach aimed at assessing companies' transition preparedness. The aim is to uncover and realise companies' social and environmental value next to their financial value. However, such an approach needs to be fostered in a context of proper governance, incentives and structures. That includes the other dimensions, like performance measurement, allocation and pricing beyond near-term financials. The incorporation of ESG information into stock prices then becomes an adaptive process, dependent on the number of fundamental analysts, how they have their decisions determined by ESG factors, and the quality of their learning. The remainder of this section considers the same dimensions as in Section 2, but through the lens of their proper functioning in such a new investment paradigm.

\subsection{Pricing: from $E M H$ to $A M H$}

The adaptive markets hypothesis (AMH) provides an alternative description of markets (Lo 2017). Contrary to the neoclassical view that individuals maximise expected utility and have rational expectations, an evolutionary perspective makes considerably more modest claims. The degree of market efficiency depends on an evolutionary model of individuals adapting to a changing environment. Prices reflect as much information as dictated by the combination of environmental conditions and the number and nature of distinct groups of market participants, each behaving in a common manner and having 
a common investment horizon. For example, retail investors, institutional investors, market makers and hedge fund managers can be seen as distinct groups with differing investment horizons. If multiple groups (or the members of a single highly populous group) are competing within a single market, that market is likely to be highly efficient. If, on the other hand, a small number of groups are active in a given market, that market will be less efficient. The adaptive markets hypothesis can explain how new risks, such as environmental risks, are not yet fully priced in, as not enough investors are examining these new risks. Indeed, Andersson, Bolton, and Samama (2016) find that carbon risk is hardly priced by markets, which they attribute to limited awareness of carbon risk among (institutional) investors. Hong, $\mathrm{Li}$, and $\mathrm{Xu}$ (2016) find that markets that are inexperienced with climate change tend to underreact to risks brought on or exacerbated by climate change.

\subsection{Allocation: from factors to investing for long-term value creation}

However smart factor models and indices may be, they offer poor proxies of what we truly want: long-term value creation. Indices are an attempt to insert ESG considerations, and they are a moderate success in that they at least shift away capital from some of the worst industries and companies. There is potential in dynamic indices that adapt portfolios according to pre-set rules, but their effectiveness too depends on the availability of better data, for which we need better performance management (section 3.3), deeper ESG integration (section 3.4) and stronger signals from active management - the backbone of investing for long term value creation (section 3.5).

Private equity partly shows the way: private equity investors look into companies and analyse future prospects (which could include transition preparedness), while taking a step away from financial markets, short-term metrics and portfolios. It means deviating much more from benchmarks. This is a path taken not just by sustainability investors, but also by several investors looking for better 'alpha opportunities' in less well-known companies that are not covered by several sell-side analysts. Cremers and Pareek (2016) show that investing away from the benchmark (with high active share, as they call it) combined with a patient investment strategy (with holding duration of over two years) generates on average an outperformance of over $2 \%$ per year.

Governance plays an important role here, not just as a major consideration when assessing potential investee companies, ${ }^{2}$ but also at the investors themselves. There, long-term value creation should be the main objective and enshrined in fiduciary duty, prospectuses, employee incentives and performance measurement.

\subsection{Performance measurement: from short-term financial to long-term financial and extrafinancial}

\subsubsection{Alternative measures of financial performance}

Investors face an information problem when judging the performance of their fund manager. One way of mitigating that problem is by benchmarking fund performance, either to others in the industry or to an industry-wide index. That is an important reason why relative return benchmarking and index-tracking is commonplace (Haldane 2014). The resulting problem is that funds are reduced to a few simple backward 
looking metrics, which gives incentives for taking shortcuts, without real accountability. Still, those metrics are not entirely without merit. So what to do with them? A possible solution lies in using those same metrics in a more flexible, slightly adapted way, while being cognisant of their limitations (e.g. only measuring the financial dimension). For example, instead of measuring performance against a single benchmark, one could use:

- A range of indices instead of a single one;

- A peer group of comparable competitor funds;

- An absolute return target, possibly corrected for an absolute risk metric.

An absolute return target is appealing as it is often more closely aligned with the goals of the beneficiaries, which are typically in the realm of building capital over the long run rather than beating indices. Jordà et al. (2017) find a long-term average return on equity of about $7 \%$ in a cross-country study. An absolute return target could, for example, be $7 \%$ over 5 year cycles. An absolute return target is not the holy grail of performance measurement, but simply switching perspective and putting performance in a wider context is valuable.

\subsubsection{Extrafinancial performance}

It is crucial to also have non-financial performance measurement, as we aim for optimisation of the financial, social and environmental dimensions given risk. Ways to do that include:

(1) Performance on specific key performance indicators (KPIs);

(2) Contribution to global sustainability goals.

3.3.2.1. Performance on specific KPIs. Investors increasingly consider company performance on specific KPIs pertaining to components of E, S and G. For example, on E, many companies now report their scope 1,2, and $3 \mathrm{CO}_{2}$ emissions following to the Greenhouse Gas Protocol (WRI 2015), and these data are fed into the Bloomberg data system available to a large part of the institutional investment community (Bloomberg 2013). To a lesser extent, this also applies to water and waste data (Bloomberg 2015). On S, there is increasing reporting of data points like employee attrition, percentage women on the workforce, job creation and safety data, like lost time injury frequency rates (LTIFR). ${ }^{3}$ On G, there is, for example, the number of independent directors, gender balance and voting rules to consider.

It is encouraging to see such data increasingly becoming available and indeed analysed. But there are also limitations to analysing the performance on specific KPIs. First, each one of the KPIs is too narrow individually. As they pertain to specific components of performance, their meaning on a standalone basis is inherently insufficient to obtain a holistic view of sustainability performance. Second, sustainability is highly context specific, making KPIs very hard to compare across companies and industries. The 'normal' values of these KPIs are very much affected by the nature of a firm's activities, and also by where the boundaries of the firm are drawn. For example, safety issues are much more of a 
concern for metals and mining companies than for financial institutions. Pryshlakivsky and Searcy (2017) provide a list of types of such contingencies. Third, the KPIs in question may not measure all that should be measured. Fourth, it is not clear if performance on certain KPIs means a sufficient contribution to achieving a more sustainable model. As Pryshlakivsky and Searcy (2017) find, these indicators tend to be self-referential rather than context-based. In fact, when investigating the sustainability reports issued by sustainability leader companies in Canada, they found none of the 463 environmental indicators identified to be context-based.

In sum, reporting on sustainability KPIs is still in its infancy. Too often, companies produce sustainability reports with data on immaterial issues that happen to be measurable. A dramatic improvement in reporting is needed and this should be a focus point in company engagement. Such improved reporting should be context-based and show to what extent a company harms or helps global and local sustainability goals.

\subsubsection{Contribution to local and global sustainability goals (context-based). As men-} tioned above, a problem with specific KPIs is that it is often not clear what performance is good enough. However, the planetary boundaries and the 17 UN Sustainable Development Goals (SDGs) are global sustainability goals that provide a context for assessing just that. They do require a translation to the meso level of specific industries and the micro level of the individual corporation though. What is the current contribution of a particular company right now? And what should its contribution be? Is it doing enough? And is its business model fit for the transition to a more sustainable economic model? Frameworks like Future-Fit (2018) and Reporting 3.0 (2018) give valuable guidance on how to answer those questions and report on them. But even the most advanced sustainability reporting companies have only just begun to explore these frameworks. Danish pharmaceutical company Novo Nordisk is a pioneer as it has recently completed a Future-Fit assessment and will report on it.

\subsection{ESG considerations: from ESG as an overlay to assessing transition preparedness}

In Section 3.2, we argue for active management in concentrated portfolios, aimed at assessing transition preparedness. In this section we expand on what transition preparedness is, how to assess it, and how to achieve the change in methods and thinking that is required for it.

\subsubsection{What is transition preparedness?}

Transition prepared means that a company's business model is either already fit for, or sufficiently flexible to successfully adapt to, a more sustainable economy. A typical example of a transition prepared company is Novozymes. This enzyme maker helps its clients to save energy and avoid 80 million tons of $\mathrm{CO}_{2}$. It currently gets paid for the energy savings, but will be paid even better in case of a considerably high $\mathrm{CO}_{2}$ price (Schoenmaker and Schramade 2019). By contrast, most airlines are not transition prepared. They will suffer massive losses in case of a significant $\mathrm{CO}_{2}$ price and seem to lack the options to avoid such a scenario (see the Air France-KLM case study with scenario analysis, Schramade 2019). Other cases are less obvious. The typical fast food chain is not 
ready for a world with high sugar and salt prices (due to taxes on them to reduce intake). But it might be experimenting with food that is tasty, affordable and healthy - thereby creating the option to survive such a scenario, and turn out to be transition prepared after all.

\subsubsection{Assessing transition preparedness and implications for methods}

Assessing a company's transition preparedness is not easy. The traditional tools are still needed, but do not suffice. Investors have to look at companies through a different lens, and go beyond traditional financial statement analysis and inserting some ESG ratings. It requires an investment analyst to investigate a company's externalities and their likelihood of internalisation; the materiality of a company's ESG issues and how well the company manages these ESG issues; what issues are in or outside of management's control; what scenarios might occur with what implications and what probabilities. The ultimate question is: can and will the company's business model be adapted to a sustainable economy? This can be assessed at the company level but hitherto only in a diagnostic way (Schramade 2016). This means that one needs an expert, like a fundamental analyst, to make a judgement call as to a company's preparedness. As we lack objective and scalable metrics for preparedness, it is very challenging to make an assessment at the portfolio or market level. Improved metrics and classifications are needed.

Figure 3 provides a simplified illustration of ESG analysis at the company and industry level. An analyst starts by identifying the company's material ESG issues, and subsequently assesses those issues in both qualitative and quantitative ways to arrive at their financial impact. While this analysis still falls short of full transition preparedness analysis, it does show that quantification is not a mechanical process that can easily be put into a formula.

Transition preparedness analysis is impossible with a passive investment approach and nearly impossible with a quant approach. There are several reasons for this. First, ratings are of limited use, as argued before. Second, there is a lack of universally relevant indicators. For quant and passive approaches to be meaningful in assessing transition

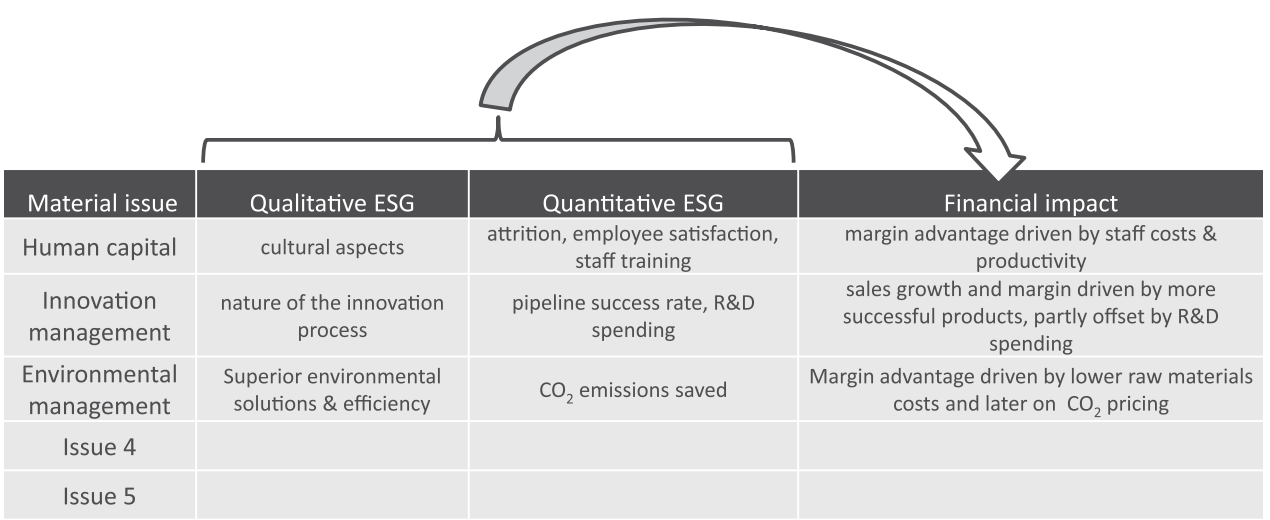

Figure 3. Financial impact of qualitative and quantitative ESG information. Note: The first step is identifying the company's material ESG issues. The second step is assessing those issues in both qualitative and quantitative ways to arrive at their financial impact (the final step). Source: NN Investment Partners. 
preparedness, they require indicators that 'work' at the market level, i.e. are relevant across companies and sectors. But so far, these indicators are rare because materiality is industry or even company specific. Where quant ESG is successful, it is mostly at tracking shortterm ESG momentum (Kaiser 2017) often without a theoretical model or clear thought behind it, let alone a view on transitions. However, it can be very useful in a complementary role to fundamental analysis.

\subsubsection{Achieving a change in mindsets and methods}

While transition preparedness analysis is possible with an active approach, unfortunately only very few do it (Cappucci 2017; Mooij 2017b). Ironically, part of the reason is that the low relevance of ratings has made many analysts overly sceptical of ESG. Unfortunately, that scepticism does not stimulate them to dig deeper themselves. So, a change of mindsets is needed, which can be achieved by integrated sustainable finance education and incentives from governance and regulation.

Finance courses at business schools and universities are still mostly taught from an EMH perspective, with little reference to sustainability or even behavioural insights. It would be a major step forward if (both regular and executive) students were taught in the spirit of this article in at least one of their finance courses - and with plenty of real life company examples for students to apply the new approach in practice.

Most corporate governance frameworks, corporate incentives and financial regulations are squarely aimed at financial performance and financial stability. It would be most helpful if regulators' goals were widened to include the prosperity and survival of the societies whose financial stability they are supposed to protect. This would be prudent as financial stability cannot exist in a failing society. Similarly, the financial industry should have a wider concept of fiduciary duty. This is a powerful tool as institutions tend to stick very strictly to their fiduciary duty. Indeed, the High Level Expert Group on Sustainable Finance (2018) recommends incorporating sustainability in the fiduciary duty of institutional investors (and their asset managers) towards their beneficiaries and clients.

On the reporting side, companies should be required to at least report on their material ESG issues, allowing analysts to better assess their transition preparedness. Eventually, companies should report on their full societal value, ideally providing an integrated $\mathrm{P} \& \mathrm{~L}$ and an integrated balance sheet. That road is long, but sustainable accounting initiatives like SASB and IIRC are helpful. However, given the importance of context, it is probably wise not to standardise too early, as it would stifle creativity and innovation in reporting. Rather, regulators are advised to require companies to answer a short list of simple but tough questions.

All this needs to change and it will take time, but partly the change process will take care of itself. The fact that very few do transition preparedness analysis, and that quants cannot do it, is also an opportunity for very good financial performance (alpha generation in Figure 4) - just like any use of valuable additional tools and data that most other market participants do not use. This is adaptation at work. Over time, quant and even passive will get better at it, as ratings are expected to improve. Figure 4 provides a dynamic picture of the availability of qualitative and quantitative ESG data. The lack of available data is very large now, but should diminish over time in line with the adaptive 


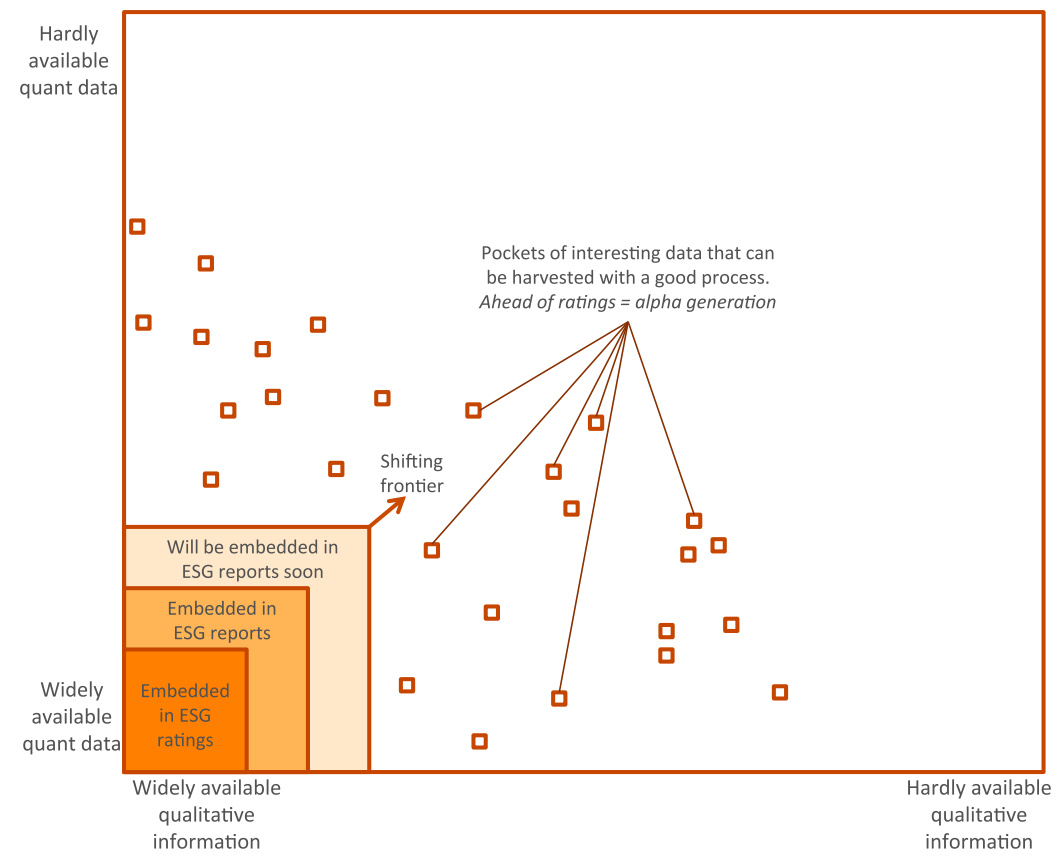

Figure 4. The increasing availability of ESG data.

markets hypothesis (Lo 2017), with pockets of poorly used (and poorly available) data as inefficiencies and opportunities to be exploited.

ESG integration can be complemented by engagement with investee companies (see Section 3.5 below) to reap the full benefits of ESG research. However, for that to happen, we need a change of governance and incentives in the investment chain, which is overly long and complicated.

\subsection{Favoured approach: from passive to active management in concentrated portfolios with deep engagement}

Compared to passive investing, active management has superior potential for achieving long term value creation. Unfortunately, that potential is often not realised in practice, as most active managers are still stuck in the current paradigm. Those active managers that do realise that potential can still differ from each other in terms of say culture and investment strategies. But two elements seem needed for achieving long term value creation: concentrated portfolios and deep engagement.

\subsubsection{Concentrated portfolios}

By its nature, thorough fundamental ESG analysis can be done for a limited number of companies only, resulting in more concentrated portfolios. In a large cross-country study of holdings of institutional investors, Choi et al. (2017) find that concentrated investment strategies in international markets result in positive risk-adjusted returns, conditional on an information advantage. Institutional investors concentrate holdings in their home market and selected foreign markets and industries as if they possess an information advantage. Institutional 
investors with higher learning capacity (i.e. skilled investors) form more concentrated portfolios. These results suggest, in contrast to traditional asset pricing theory and in support of information advantage theory, that concentrated investment strategies can be optimal.

Statman (2004) shows that a well-diversified stock portfolio needs to include just 50100 stocks to eliminate idiosyncratic or unsystematic variance of stock returns. There are smaller benefits of diversification beyond those 100 stocks, but they are exhausted when the number of stocks surpasses 300 stocks (see Figure 5). Risk management should monitor that the stocks are not overly correlated (reducing their diversification potential) and are spread over sectors and countries. Moreover, diversification gains are mainly driven by a well-balanced allocation over different asset classes, like equities, bonds and alternative investments (i.e. real estate, private equity, hedge funds, commodities and infrastructure) (see for example Jacobs, Müller, and Weber 2014). Thus, for diversification it is more important to have a concentrated portfolio in each asset class than to have a very diversified portfolio (beyond 100 securities) in a single asset class.

Moreover, diversification comes at a cost, which might cancel out the low fee costs of passive investing. First, diversification reduces selectiveness, which disappears almost completely in passive strategies. In passive investing, it is not yet possible to invest only in the sub-set of companies that are able and willing to transform towards sustainable business models. However, it is possible to build passive investments on ESG adjusted indices that exclude the worst industries, such as coal and tobacco. This negative screening is a rather crude measure, but does steer investment away from the worst companies. And over time such indices should become more sophisticated.

Second, the larger the number of stocks owned, the harder it becomes to have sufficient knowledge about, and really engage with, multiple companies in the portfolio. Third, on an aggregated level, widely diversified portfolios result in inadequate monitoring of corporate management teams. A free-rider problem arises as small percentage stakes mean that few investors have sufficient incentives to monitor management.

\subsubsection{Engagement}

Another element of an active investment approach is effective engagement with investee companies on the long-term, both behind the scenes by meeting with companies and in

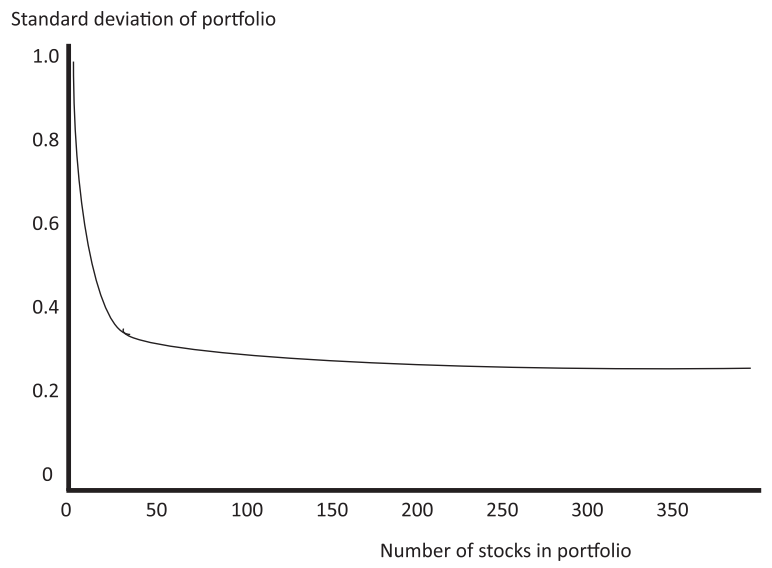

Figure 5. Diminishing benefits from diversification. Source: Statman (2004). 
the annual general meeting by voting (McCahery, Sautner, and Starks 2016). Investors and companies can exchange not only funds, but also ideas on how best to put these funds to work. Even the companies that are already on a journey to become more sustainable still need help in developing the most useful and cost-effective disclosure practices. And while lots of investors want companies to provide more and better disclosure of their ESG exposures, they tend to shy away from giving explicit recommendations. So, investors need to become more active in communicating their demands and preferences for information (Higgins et al. 2017).

However, such engagement is costly. It requires human resources, expertise and time of the asset managers, ideally delivered in cooperation between portfolio managers, investment analysts and sustainability specialists. This is only feasible in a concentrated and actively managed portfolio: 100 stocks can be followed and engaged by a small team of people who work closely together. Engagement needs to be actively managed to allow the investment case knowledge of portfolio managers and investment analysts to be integrated into the engagement.

In practice, this happens at very few financial firms. Rather, engagement is typically done at the group level for a small percentage of the holdings and by a team of engagement specialists that lack knowledge of the firms' investment cases and hence miss important points, resulting in engagement on matters that are often not material. As passive portfolios typically have thousands of stocks, the best a passive asset owner can do in practice is to vote for all those companies along the guidelines of a proxy advisor and do engagement with a few dozen companies.

Large (passive) asset managers could have a strong impact on promoting sustainable business practices by their size. However, US evidence on proxy voting (Bolton et al. 2019) indicates that mutual funds, including the large passive asset managers (BlackRock, Vanguard and State Street), are more narrowly 'money conscious' investors that often vote with management, while pensions funds support a more social and environment-friendly orientation of the firm. Moreover, Bebchuk and Hirst (2019) show that mutual funds have an incentive to under-invest in stewardship, as they bear the full cost but only get a tiny part of the benefit. ${ }^{4}$ For Europe, Dimson, Karakaş, and Li (2018) find that institutional investors, in particular pension funds, are active in coordinated engagement to influence firms on environmental and social issues. The large US mutual funds, which also have a large presence in Europe, are absent in these coordinated engagements.

\subsubsection{Investment strategies: channelling capital to sustainability leaders or to laggards that are set to improve?}

One can employ a multitude of strategies to invest for long term value creation. And a major question is whether it is better to invest in companies that already do well or in laggards that look set to improve. On the one hand, investing in the leaders likely implies that the capital will be used in a sustainable way, that risk is lower, and that good behaviour is rewarded. On the other hand, investing in the laggards means that the invested capital could make more of a difference. Moreover, the latter strategy may also be more profitable: the European Centre for Corporate Engagement (ECCE 2016) finds that companies with improving sustainability ratings outperform the stock market, while companies with already high ratings do not outperform it (with the caveat of the flaws of ratings). Of 
course, the answer does not need to be binary, as one could also invest in a mix of leaders and improving laggards.

Investing in the laggards does raise additional questions. First, how to determine the size and likelihood of the improvement? Second, will that improvement be good enough to be consistent with global sustainability development goals or is it perhaps better if the company perishes? Hence, where is the demarcation between laggards that really want to (and will) improve significantly and the laggards that are beyond salvation?

\subsection{Investment chains: from long \& complex to short \& simple}

Building on our stylised investment chain in Figure 2, Figure 6 contrasts the ideal and the current investment chain. The middle column illustrates the ideal investment chain from a

\begin{tabular}{|c|c|c|}
\hline \multicolumn{3}{|l|}{ Beneficiaries } \\
\hline Asset owner & Ideally & Often \\
\hline Horizon & Decades & Quarter \\
\hline Maximises & $\mathrm{IV}=\mathrm{FV}+\mathrm{SV}+\mathrm{EV}$ & FV \\
\hline Internal structure & Simple and flat & Bureaucratic \\
\hline External structure & $\begin{array}{l}\text { Few asset managers and con- } \\
\text { sultants }\end{array}$ & $\begin{array}{l}\text { Hires many asset managers and con- } \\
\text { sultants }\end{array}$ \\
\hline $\begin{array}{l}\text { Performance met- } \\
\text { rics }\end{array}$ & Sophisticated and nuanced & $\begin{array}{l}\text { A few market metrics and perhaps } \\
\text { ratings }\end{array}$ \\
\hline Asset manager & Ideally & Often \\
\hline Horizon & Years & Quarter \\
\hline Maximises & $\mathrm{IV}=\mathrm{FV}+\mathrm{SV}+\mathrm{EV}$ & $\mathrm{FV}$ \\
\hline $\begin{array}{l}\text { Investment ap- } \\
\text { proaches }\end{array}$ & $\begin{array}{l}\text { - Consistent and transpar- } \\
\text { ent } \\
\text { - Concentrated portfolio }\end{array}$ & $\begin{array}{l}\text { Do not do as they say } \\
\text { Small holdings in large port-fo- } \\
\text { lios, close to the benchmark }\end{array}$ \\
\hline $\begin{array}{l}\text { Engagement ap- } \\
\text { proaches }\end{array}$ & $\begin{array}{l}\text { On all holdings, based on ma- } \\
\text { teriality and linked to invest- } \\
\text { ment decisions }\end{array}$ & $\begin{array}{l}\text { Proxy voting and some engagement } \\
\text { with a few holdings, unrelated to in- } \\
\text { vestment decisions }\end{array}$ \\
\hline Investee company & Ideally & Often \\
\hline Horizon & $\begin{array}{l}\text { Decades, but well balanced } \\
\text { with short run execution }\end{array}$ & $\begin{array}{l}\text { Own tenure, but blame shareholders } \\
\text { for short-termism }\end{array}$ \\
\hline Maximises & $I V=F V+S V+E V$ & FV in the sense of earnings per share \\
\hline Compensation & $\begin{array}{l}\text { Aligned with long term value } \\
\text { creation mandate, strategy, } \\
\text { business model and invest- } \\
\text { ment decisions }\end{array}$ & $\begin{array}{l}\text { Based on short term metrics such as } \\
\text { EPS; no claw-backs }\end{array}$ \\
\hline Reporting & Integrated reporting & Traditional reporting \\
\hline
\end{tabular}

Note: IV = Integrated Value; FV = Financial Value (F), SV = Social Value (S) and EV = Environmental Value (E).

Figure 6. Ideal versus actual investment chains and their components. Note: IV = Integrated Value; FV = Financial Value; SV = Social Value; $\mathrm{EV}=$ Environmental Value. 
sustainable finance perspective. The asset owner (e.g. a pension fund or a retail client) is a long-term investor, who cares about financial, social and environmental returns. If it has sufficient scale, the asset owner can do its asset management in house. If not, the asset owner appoints an asset manager, who invests on his or her behalf. The asset owner asks the asset manager to report on financial and ESG returns, including carbon-related financial disclosures of the invested companies. The asset manager also actively engages with the company to promote sustainable business practices.

The final party in the investment chain is the company, which ideally has a board that has adopted a sustainable business model, and applies integrated reporting. Closing the circle, the integrated report provides the necessary information on financial, social and environmental values to the asset manager, who can report back to the asset owner. All parts of the chain are expected to understand the important aspects of sustainable finance and its nuances.

This ideal investment chain does not exist in practice, and the right column of Figure 6 is a more realistic representation of current investment chains. First, there are multiple parties in the chain: both within each nexus of the chain and across multiple nexuses (an asset manager may delegate the investment to another asset manager and so on). An example of the latter is an asset manager for a pension fund, who invests in a hedge fund or private equity. There may be so many delegates that monitoring becomes very hard. Second, performance metrics tend to be narrow. For example, the performance of the asset manager is often measured against a clearly articulated benchmark. Third, incentives are shorter term than desirable given fiduciary duty and investment goals.

\subsection{Long-term investing in practice}

Institutional investors are finding out that they can realise long-term investment returns by investing in and engaging with companies that are capable of adding value over the long-term, thereby having a positive effect on the value of their portfolios and on society.

In addition, asset owners can reduce the complexity of their investment chains by relying less (or not at all) on external asset managers and consultants. For example, many Canadian pension funds have insourced much of their asset management, achieving better returns and lower overall costs. Their higher salary costs are more than compensated by lower external fees, which is also known as the Canada effect (Ambachtsheer 2016).

A nice example of how long-term investing can be done in practice is provided by Alecta (Schoenmaker and Schramade 2019). This large Swedish pension fund (€81 billion assets under management in 2016) has an investment strategy squarely aimed at long-term value creation. The pension fund adopts a 15-20 year perspective on the asset side and applies ESG integration in its investment process.

Active management of a limited number of shareholdings (104 listed shareholdings in 2016) is central to Alecta's asset management model. This active management is done through independent in-house analysis, focusing on the absolute return and risks of investments using a 5-year average. This has significant advantages compared with index management. Each investment decision is preceded by a sustainability review of the company being considered. When Alecta invests in a company, it often becomes one of the largest shareholders, which enables it to engage in a close dialogue and influence the company in the desired direction. 
Alecta's total management costs are $0.09 \%$ of assets under management, of which investment management costs are $0.02 \%$. Alecta can keep its operating costs very low, because it has cut out external asset managers and consultants. While a large pension fund like Alecta has sufficient scale to do this, it might be more challenging for smaller pension funds to do this. Such smaller players as well as retail investors will have to rely on asset managers.

\subsection{Role for asset management: truly performing the social function of finance}

A new paradigm has serious implications for the role of asset management. The industry can add a lot of value and build trust by offering active management aimed at long term value creation, truly performing the social function of finance. However, for that potential to be met, the industry needs to step up its efforts in terms of the depth and breadth of transition preparedness analysis, its engagement, and the concentration of its portfolios. Ideally, this feeds into passive products as well, making the two types of investment mutually reinforcing.

In addition, asset managers will have to make products available to the public that not only do the above, but also do it in a way that is credible and verifiable, which is quite a challenge indeed as even professionals are confused by the current state of the field. This task is not merely hypothetical since client demand for sustainable and impact investing products is strongly on the rise. The younger members of wealth families seem particularly eager to invest their capital in ways that make the world a better place.

\section{Conclusions}

The financial system is instrumental in achieving the transition to a sustainable economy. To fulfil that societal role, investors have to move from a focus on shortterm financials, towards long term value creation. This requires doing fundamental research into the investee companies. While several financial institutions aim to move to investing for long-term value creation, traditional investment approaches are still built and run on the concepts of efficient markets and portfolio theory. Moreover, long and complicated investment chains exacerbate the reliance on market metrics.

This article identifies the contours of an alternative investment paradigm, aimed at investing for long-term value creation. Its ingredients are adaptive markets thinking, short investment chains, and active management in concentrated portfolios, with deep engagement aimed at assessing transition preparedness.

These alternative ways are available, but not yet widely used. Some are showing the way, but the asset management industry has yet to deliver its added value. Achieving paradigm change requires a change of mindsets. For this, integrated sustainable finance education and incentives from governance and regulation are needed. Finance education at universities is not much different from what it was two decades ago. That needs to change. We need students that are trained in assessing transition preparedness; who are able to look beyond both the numbers and the fuss. That requires examples, training and sharing of best practices. And we need an evolution in governance, incentives and regulation that stimulates long-term value creation. 


\section{Notes}

1. Chunka Mui, 'PG\&E is just the first of many climate change bankruptcies', Forbes, January 2019.

2. Indeed, Shrivastava and Addas (2014) find that strong governance can engender high performance on $\mathrm{E}$ and $\mathrm{S}$.

3. The lost time injury frequency rate measures the number of lost time injuries occurring in a workplace per 1 million hours worked. An LTIFR of 7, for example, shows that 7 lost time injuries occur on a jobsite every 1 million work hours.

4. While an asset owner receives a proportional increase in value of a company due to engagement, the asset manager (which charges a small fee on assets under management) only receives a tiny amount (the fee times the proportional increase in company value).

\section{Acknowledgement}

The authors are grateful to Magnus Billing, Mathijs van Dijk, Han van der Hoorn, Rob Lake and Marno Verbeek, two anonymous reviewers and seminar participants at the University of Zurich and Vienna University for very useful comments.

\section{Disclosure statement}

No potential conflict of interest was reported by the authors.

\section{ORCID}

Willem Schramade (i) http://orcid.org/0000-0003-2004-4409

\section{References}

Ambachtsheer, K. 2016. The Future of Pension Management. New York: Wiley.

Andersson, M., P. Bolton, and F. Samama. 2016. "Hedging Climate Risk." Financial Analysts Journal 72 (3): 13-32.

Barberis, N., and R. Thaler. 2003. “A Survey of Behavioral Finance.” In Handbook of the Economics of Finance. Vol. 1, edited by G. Constantinides, M. Harris, and R. Stulz, 1053-1128. Amsterdam: Elsevier.

Bebchuk, L., and S. Hirst. 2019. "Index Funds and the Future of Corporate Governance: Theory, Evidence, and Policy." Columbia Law Review 119: forthcoming.

Bloomberg. 2013. Bloomberg Carbon Risk Valuation Tool. New York: Bloomberg.

Bloomberg. 2015. Water Risk Valuation Tool: Integrating Natural Capital Limits into Financial Analysis of Mining Stocks. New York: Bloomberg.

Bolton, P., T. Li, E. Ravina, and H. Rosenthal. 2019. "Investor Ideology." CEPR Discussion Paper, DP12633.

Cappucci, M. 2017. "The ESG Integration Paradox." Working Paper. Boston, MA: Harvard Management Company.

Choi, N., M. Fedenia, H. Skiba, and T. Sokolyk. 2017. "Portfolio Concentration and Performance of Institutional Investors Worldwide.” Journal of Financial Economics 123 (1): 189-208.

Clark, G., A. Feiner, and M. Viehs. 2015. "From the Stockholder to the Stakeholder: How Sustainability Can Drive Financial Outperformance." Working Paper, Smith School of Enterprise and the Environment, University of Oxford. http://ssrn.com/abstract=2508281.

Cohen, F., K. Hamilton, C. Hepburn, F. Sperling, and A. Teytelboym. 2017. "The Wealth of Nature: Increasing National Wealth and Reducing Risk by Measuring and Managing Natural Capital." Working Paper, Institute for New Economic Thinking (INET) at the Oxford Martin School and Smith School of Enterprise and the Environment. 
Cort, T. 2018. "Incentivizing the Direction of Multi-Capital Toward Inclusive Capitalism." Journal of Sustainable Finance \& Investment 8 (3): 203-212.

Cremers, M., and A. Pareek. 2016. "Patient Capital Outperformance: The Investment Skill of High Active Share Managers Who Trade Infrequently." Journal of Financial Economics 122 (2): 288-306.

Dimson, E., O. Karakaş, and X. Li. 2018. “Coordinated Engagements.” Working Paper. https://ssrn. com/abstract $=3209072$.

Dyllick, T., and K. Muff. 2016. "Clarifying the Meaning of Sustainable Business." Organization and Environment 29 (2): 156-174.

ECCE (European Centre for Corporate Engagement). 2016. The Materiality of ESG Factors for Equity Investment Decisions: Academic Evidence. Maastricht: Maastricht University.

Elton, E., M. Gruber, S. Brown, and W. Goetzmann. 2014. Modern Portfolio Theory and Investment Analysis. 9th ed. New Jersey: Wiley.

Fama, E. 1970. "Efficient Capital Markets: A Review of Theory and Empirical Work." The Journal of Finance 25 (2): 383-417.

Friedman, M. 1970. “The Social Responsibility of Business is to Increase its Profits.” The New York Times Magazine, September 13.

Future-Fit. 2018. Methodology Guide. https://futurefitbusiness.org/resources/.

Haldane, A. 2014. "The Age of Asset Management." Speech at the London Business School, London, April 4.

Hart, O., and L. Zingales. 2017. "Companies Should Maximize Shareholder Welfare Not Market Value." Journal of Law, Finance, and Accounting 2 (2): 247-275.

Higgins, K., J. White, A. Beller, and M. Schapiro. 2017. "The SEC and Improving Sustainability Reporting." Journal of Applied Corporate Finance 29 (2): 22-31.

High Level Expert Group on Sustainable Finance. 2018. Financing a Sustainable European Economy. Final Report. Brussels: European Union.

Hong, H., F. Li, and J. Xu. 2016. “Climate Risks and Market Efficiency.” NBER WP Nr. 22890.

Howard, J. 2016. "Painting by Numbers - The Difficulties of Measuring Sustainability." Market Insights, Schroders, London.

Jacobs, H., S. Müller, and M. Weber. 2014. "How Should Individual Investors Diversify? An Empirical Evaluation of Alternative Asset Allocation Policies." Journal of Financial Markets 19 (1): 62-85.

Jegadeesh, N., and S. Titman. 1993. "Returns to Buying Winners and Selling Losers: Implications for Stock Market Efficiency.” The Journal of Finance 48 (1): 65-91.

Jordà, O., K. Knoll, D. Kuvshinov, M. Schularick, and A. Taylor. 2017. "The Rate of Return on Everything, 1870-2015.” CEPR Discussion Paper 12509.

Kaiser, L. 2017. "Style, Momentum and ESG Investing." Working Paper. https://ssrn.com/abstract= 2993843.

Khan, M., G. Serafeim, and A. Yoon. 2016. "Corporate Sustainability: First Evidence on Materiality." The Accounting Review 91 (6): 1697-1724.

Lo, A. 2017. Adaptive Markets: Financial Evolution at the Speed of Thought. Princeton: Princeton University Press.

Markowitz, H. 1952. "Portfolio Selection.” Journal of Finance 7 (1): 77-91.

McCahery, J., Z. Sautner, and L. Starks. 2016. "Behind the Scenes: The Corporate Governance Preferences of Institutional Investors." The Journal of Finance 71 (6): 2905-2932.

Mooij, S. 2017a. "The ESG Initiative Industry; Vice or Virtue in the Adoption of Responsible Investment?” Journal of Environmental Investing 8 (1): 331-367.

Mooij, S. 2017b. "Asset Owners and the Diffusion of Responsible Investment. What Explains the Low Rate of Adoption?" Working Paper, Oxford University.

Neal, D., and G. Warren. 2015. "Long-term Investing as an Agency Problem.” CIFR Paper No. 063/ 2015, Centre for International Finance and Regulation, Sydney.

Pryshlakivsky, J., and C. Searcy. 2017. "A Heuristic Model for Establishing Trade-Offs in Corporate Sustainability Performance Measurement Systems.” Journal of Business Ethics 144 (2): 323-342.

Reporting 3.0. 2018. Blueprint 5: Transformation Journey. https://reporting3.org/publications/. 
Schoenmaker, D. 2018. “A Framework for Sustainable Finance.” CEPR Discussion Paper, DP12603. Schoenmaker, D., and W. Schramade. 2019. Principles of Sustainable Finance. Oxford: Oxford University Press.

Schramade, W. 2016. "Bridging Sustainability and Finance: The Value Driver Adjustment Approach.” Journal of Applied Corporate Finance 28 (2): 17-28.

Schramade, W. 2019. "A Sustainable Finance Case Study: Air France-KLM.” Working Paper, Erasmus Platform for Sustainable Value Creation, Erasmus University Rotterdam.

Shrivastava, P., and A. Addas. 2014. "The Impact of Corporate Governance on Sustainability Performance." Journal of Sustainable Finance \& Investment 4 (1): 21-37.

Simon, M. 2017. Real Impact: The New Economics of Social Change. New York: Nation Books.

Statman, M. 2004. “The Diversification Puzzle." Financial Analysts Journal 60 (4): 44-53.

Tirole, J. 2017. Economics for the Common Good. Princeton: Princeton University Press.

Tversky, A., and D. Kahneman. 1973. "Availability: A Heuristic for Judging Frequency and Probability.” Cognitive Psychology 5 (2): 207-232.

WRI (World Resources Institute). 2015. Greenhouse Gas Protocol. Washington, DC: World Resources Institute. 